\title{
Oxygen reserve index for non-invasive early hypoxemia detection during endotracheal intubation in intensive care: the prospective observational NESOI study
}

Hugo Hille ${ }^{1}$, Aurelie Le Thuaut ${ }^{2}$, Emmanuel Canet ${ }^{1}$, Jeremie Lemarie ${ }^{1}$, Laura Crosby ${ }^{1}$, Gregoire Ottavy $^{1}$, Charlotte Garret', Maelle Martin', Amelie Seguin', Pauline Lamouche-Wilquin', Jean Morin', Olivier Zambon', Arnaud-Felix Miaihle ${ }^{1}$, Jean Reignier ${ }^{1}$ and Jean-Baptiste Lascarrou ${ }^{1,3,4^{*}}$ (B)

\begin{abstract}
Background: To evaluate the ability of the oxygen reserve index (ORI) to predict the occurrence of mild hypoxemia (defined as $\mathrm{SpO}_{2}<97 \%$ ) during endotracheal intubation (ETI) of patients in the intensive care unit (ICU).

Methods: This observational single-centre study included patients without hypoxemia (defined as $\mathrm{SpO}_{2} / \mathrm{FiO}_{2}>214$ ) who required ETI in the ICU. Patients were followed during preoxygenation and ETI then until hospital discharge and/ or day 28. We recorded cases of mild hypoxemia, moderate $\left(\mathrm{SpO}_{2}<90 \%\right)$ and severe $\left(\mathrm{SpO}_{2}<80 \%\right)$ hypoxemia, moderate arterial hypotension (systolic arterial pressure $<90 \mathrm{mmHg}$ ), oesophageal intubation, aspiration, cardiac arrest, and death.
\end{abstract}

Results: Between January 2019 and July 2020, 56 patients were included prospectively and 51 patients were analysed. Twenty patients had mild hypoxemia between the end of preoxygenation and the end of intubation; in 10 of these patients, the decrease in $\mathrm{SpO}_{2}$ below $97 \%$ was preceded by an $\mathrm{ORI}<0.4$, the median time difference being $81 \mathrm{~s}$ [interquartile range, 34-146]. By multivariable analysis, a higher ORI (by 0.1 increase) value during preoxygenation was associated with absence of hypoxemia (odds ratio, $0.76 ; 95 \%$ confidence interval, $0.61 ; 0.95 ; P=0.0141$ ).

Conclusion: In non-hypoxemic patients, the 81-s [34-146] median time between the ORI decrease below 0.4 and the $\mathrm{SpO}_{2}$ decrease below $97 \%$ during apnoea may allow preventive action. A higher ORI value during preoxygenation was independently protective against hypoxemia. Whether these findings also apply to hypoxemic patients, and the clinical impact of a preoxygenation strategy based on ORI monitoring, remain to be evaluated prospectively.

Trial Registration ClinicalTrial.gov, \#NCT03600181.

Keyword: Intensive care, Intubation, Oxygenation, Monitoring

*Correspondence: jeanbaptiste.lascarrou@chu-nantes.fr

${ }^{4}$ Service de Médecine Intensive Réanimation, Centre Hospitalier Universitaire Hôtel-Dieu, 30 Bd. Jean Monnet, 44093 Nantes Cedex 1, France

Full list of author information is available at the end of the article

\section{Introduction}

Endotracheal intubation (ETI) is performed in many patients admitted to the intensive care unit (ICU), the proportion being $22 \%$ in a multicenter study [1]. The circumstances that surround ETI in the ICU are associated with a high complication rate of up to $50 \%$ [1-4]. The serious complications are severe hypoxemia (26\%), severe hypotension (25\%), cardiac arrest (1-3\%), and 
death $(0.5-3 \%)[1,4,5]$. Severe hypoxemia, which can be fatal [7], is more common when the patient is hypoxemic before intubation and/or intubation is difficult $[8,9]$.

Predicting the occurrence of hypoxemia during ETI is challenging [10]. Preoxygenation reduces the risk by prolonging the safe apnoea time and is therefore universally recommended [11, 12]. Preoxygenation consists in giving pure oxygen to wash out the nitrogen contained in the lungs at functional residual capacity. The effectiveness of preoxygenation is evaluated experimentally and in the operating room by the expired fraction of oxygen $\left(\mathrm{FeO}_{2}\right)$, but this marker has limitations in the emergency setting (sensitivity to leaks) and is not available in the ICU [13]. Recent studies have evaluated various preoxygenation devices with contradictory results $[6,14-16]$, and currently no device ensures that desaturation will not occur during intubation [17]. Pulsed oxygen saturation $\left(\mathrm{SpO}_{2}\right)$ measured by pulse oximetry-which is the parameter monitored in intensive care-only detects hypoxemia at a late stage. Thus, at present, the effectiveness of preoxygenation cannot be evaluated in intensive care. The absence and/or low quality of preoxygenation was associated with the occurrence of cardiac arrest during the peri-intubation period in a retrospective analysis of a multicentre prospective database that had 1847 ETI procedures [7]. Thus, optimising preoxygenation is a crucial goal. To optimise preoxygenation, the availability of a reliable predictor of desaturation would be valuable.

The oxygen reserve index (ORI) is a new oxygenation monitoring parameter measured continuously and noninvasively by a specific pulse oximeter device manufactured by Masimo (Irvine, CA). It provides a dimensionless index from $0.0\left(\mathrm{PaO}_{2} \geq 100 \mathrm{~mm} \mathrm{Hg}\right)$ to 1.0 $\left(\mathrm{PaO}_{2} \geq 200 \mathrm{~mm} \mathrm{O}_{2}\right)$. Thus, the ORI supplies information beyond the range explored by $\mathrm{SpO}_{2}$.

The objective of this prospective observational pilot study was to evaluate the potential role for ORI in providing early warning that hypoxemia will occur during ETI of patients in the ICU.

\section{Patients and methods Study design}

We conducted a prospective observational proof-ofconcept single-centre study. We collected the data in the medical ICU of the Nantes University Hospital (Nantes, France), which has 25 ICU beds and five intermediatecare beds.

The study was approved by our ethics committee on September, 2018 (CPP Ile de France 1, ID-RCB: 2018A01288-47) and was open to inclusion on ClinicalTrials.gov on January 30, 2019 (\#NCT03600181). Written informed consent to participation was obtained from each patient or proxy. According to French legislation, patients who were not competent and had no proxy available were included if they met the selection criteria then asked for their consent as soon as they recovered competency.

\section{Oxygen reserve index}

The oxygen reserve index (ORI) is a nondimensional index that ranges from 1 (high reserve) to 0 (no reserve) and is measured by optically detecting changes in mixed venous oxygen saturation $\left(\mathrm{SvO}_{2}\right)$ after oxygen saturation $\left(\mathrm{SaO}_{2}\right)$ reaches $100 \%$. It is measured by a multi-wavelength pulse co-oximeter placed on the tip of a finger (Rainbow SET, Masimo) [18]. The device analyses variations in the pulsatile blood absorption of incident light at both the arterial and venous levels. It is a relative indicator of $\mathrm{PaO}_{2}$ changes in the moderate hyperoxemia range. When pure oxygen is administered, $\mathrm{SaO}_{2}$ reaches $100 \%$ when $\mathrm{PaO}_{2}$ reaches $100 \mathrm{mmHg}$. Beyond that, $\mathrm{PaO}_{2}$ continues to increase, both $\mathrm{SaO}_{2}$ and $\mathrm{SpO}_{2}$ remain at $100 \%$, and the ORI increases non-linearly from 0.00 $\left(\mathrm{PaO}_{2}-100 \mathrm{~mm} \mathrm{Hg}\right)$ to $1.00\left(\mathrm{PaO}_{2}-200 \mathrm{mmHg}\right)$.

\section{Patient selection}

Inclusion criteria were ICU admission with a need for ETI and a $\mathrm{SpO}_{2} / \mathrm{FiO}_{2}$ ratio above 214. The $\mathrm{SpO}_{2} / \mathrm{FiO}_{2}$ ratio was measured during non-invasive ventilation (NIV) or high-flow oxygen therapy. For conventional oxygen therapy, the fraction of inspired oxygen $\left(\mathrm{FiO}_{2}\right)$ was calculated as follows: $\mathrm{FiO}_{2}=0.21+\mathrm{O}_{2}$ flow 0.03 [19].

Exclusion criteria were age younger than 18 years, indication to use an alternate tool to perform ETI (unstable spinal cord injury for example), insufficient time to include the patient (e.g., cardiac arrest), pregnancy or breastfeeding, being a correctional services inmate, being under guardianship, or not being covered by the French statutory health insurance system.

Patients were secondarily excluded in the event of an ORI device malfunction, failure of ORI recording by the computer, ORI remaining constant at 1 throughout preoxygenation, and $\mathrm{SpO}_{2}<97 \%$ throughout preoxygenation [20].

\section{Data collection}

Standardised forms were used to record the following data: patient's baseline characteristics [including difficult intubation criteria: Mallampati score, thyromental distance $<65 \mathrm{~mm}$, mouth opening $<35 \mathrm{~mm}$, limited cervical mobility, sleep apnoea, body mass index (BMI) > 35], main reason for ETI (neurological, respiratory, cardiovascular, or other), use of a bougie and/or other devices (e.g., laryngeal mask airway or videolaryngoscope), duration of preoxygenation, total ETI duration (from anaesthesia induction to capnography over more than three 
cycles indicating proper endotracheal tube position), and baseline $\mathrm{SpO}_{2}$. We also collected $\mathrm{SpO}_{2}$ and ORI at four time points: beginning of preoxygenation, end of preoxygenation, during ETI and just after successful ETI. $\mathrm{SpO}_{2}$ drops below 97\%, 90\%, and 80\% between anaesthesia induction and successful ETI were recorded. Complications were recorded as death, cardiac arrest, and systolic blood pressure drop to less than $90 \mathrm{mmHg}$ [21]. Casereport forms were completed in real time by a dedicated clinical research nurse. Each case report form was then introduced into an electronic file (Excel, Microsoft Corporation, Redmond, WA).

\section{Outcomes}

The primary endpoint was the time between the ORI decrease below 0.4 and the $\mathrm{SpO}_{2}$ decrease below 97\% during ETI (between the end of preoxygenation and confirmation that the tube was in the trachea). The value of 0.4 for ORI was chosen in agreement with the only available study [22].

The secondary objective of our study was to determine whether a decline in ORI during preoxygenation predicted the occurrence of $\mathrm{SpO}_{2}<97 \%$ during ETI.

\section{Intubation procedure}

Once the decision to perform ETI was made and consent obtained, an ORI device (Rainbow ${ }^{\circledR}$ Lite SET-1 Adt sensors, Revision M, Masimo) was applied to the patient's 3rd or 4th fingertip on the contralateral side of the noninvasive blood pressure monitoring device. The sensor was covered to protect it from light. $\mathrm{SpO}_{2}$ and ORI values displayed on the $\operatorname{Rad} 7^{\circledR}$ monitor were recorded every $2 \mathrm{~s}$ and transferred to a laptop computer throughout the ETI procedure. The patient's physicians were not aware of the ORI values.

ETI was performed according to the standardised protocol used in the ICU of the Nantes University Hospital [21]. The choice of the preoxygenation device, anaesthesia induction agents, and ETI device was at the discretion of the physician in charge. The recommended preoxygenation duration was $3 \mathrm{~min}$.

The procedure began with the initiation of preoxygenation and ended with confirmation that the tube was in the trachea. The end of preoxygenation was defined as the induction of anaesthesia. The duration of ETI was the time from the end of preoxygenation and confirmation by capnography of correct tube position. Neither apneic oxygenation nor apneic ventilation [23] was part of our local protocol during management of the study patients.

\section{Sample size}

In the absence of critical care data, we estimated the time to an $\mathrm{SpO}_{2}$ decrease to $97 \%$ at $60 \pm 30 \mathrm{~s}[22,24]$ and we assumed that the ORI would decrease below 0.4 (warning cut-off determined by the manufacturer and consistent with data from a paediatric study [22]), $30 \mathrm{~s}$ before $\mathrm{SpO}_{2}$ decreased below $97 \%$. We estimated the median time between these two decreases, with the $95 \%$ confidence interval (95\% CI) and an accuracy of $10 \mathrm{~s}$. Assuming a standard deviation of $30 \mathrm{~s}, 35$ patients were needed [25]. According to Szmuk et al. [22], it was expected that 28\% of patients would have a secondary exclusion criterion, and we therefore decided to include 50 patients.

\section{Statistical analysis}

Qualitative data were described as frequency and percentage and quantitative data as mean \pm SD and median [interquartile range].

The median time between the ORI decrease below 0.4 and the $\mathrm{SpO}_{2}$ decrease below 97\% during ETI was estimated with its $95 \%$ confidence interval $(95 \% \mathrm{CI})$.

The performance of the ORI for predicting $\mathrm{SpO}_{2}<$ 97\% during ETI was estimated by the area under the ROC curve with its $95 \%$ CI. To evaluate the informative value of the ORI signal, a multivariate logistic regression model with the occurrence of $\mathrm{SpO}_{2}<97 \%$ as a predictor variable was constructed. The variables included by stepdown selection were the ORI and the variables selected a priori as clinically relevant [10] (age, gender, BMI, and ETI duration).

All tests were two-tailed with a significance level of 0.05 . No imputation strategy was used. The statistical analyses were done using Stata ${ }^{\circledR}$ statistical software (version 13; StataCorp LP, College Station, TX).

\section{Results}

\section{Patients}

Between February 2019 and July 2020, 56 patients were included. Main reasons for non-inclusion were $\mathrm{SpO}_{2} /$ $\mathrm{FiO}_{2}<214(n=114,76 \%)$ followed by omission $(n=$ 21, 14\%) (Additional file 1: Figure S1). Among the 56 included patients, 5 were secondarily excluded, leaving 51 for in the analysis. Table 1 reports their main features. No patient had a history of difficult intubation, the Mallampati score was $1 / 4$ in $36(70.6 \%)$ patients, and 22 (43\%) patients met none of the criteria for difficult ETI.

\section{Procedure}

Preoxygenation was performed with a bag valve mask $(n=40,78.4 \%)$ or NIV $(n=11,21.6 \%)$ and ETI with a standard laryngoscope $(n=48,94.1 \%)$ or a videolaryngoscope $(n=3,5.9 \%)$. A bougie was used in $16(31.4 \%)$ patients. The anaesthetic agents used for induction were etomidate in $43(84.3 \%)$ patients and propofol in 8 patients (15.7\%), for hypnosis; for neuromuscular blockade, succinylcholine was used in 41 (80.4\%) patients and 
Table 1 Patients' baseline characteristics

\begin{tabular}{|c|c|}
\hline Age, years & $59[43-66]$ \\
\hline Gender, female & $22(43.14 \%)$ \\
\hline Body mass index, $\mathrm{kg} \mathrm{m}^{-2}$ & $24.22[20.81-29.73]$ \\
\hline \multicolumn{2}{|l|}{ Past medical history } \\
\hline Active smoking & $13(25.49 \%)$ \\
\hline Chronic arterial hypertension & $12(23.52 \%)$ \\
\hline Diabetes mellitus & $7(13.72 \%)$ \\
\hline Cancer and/or immunodepression & $9(17.64 \%)$ \\
\hline Cirrhosis & $9(17.64 \%)$ \\
\hline Chronic obstructive apnoea & $4(7.84 \%)$ \\
\hline History of hepatic encephalopathy & $3(5.88 \%)$ \\
\hline Chronic respiratory disease & $2(3.92 \%)$ \\
\hline Neuromuscular disease & $2(3.92 \%)$ \\
\hline Other & $9(17.64 \%)$ \\
\hline \multicolumn{2}{|l|}{ Reason for ICU admission } \\
\hline Acute neurologic failure & $29(56.80 \%)$ \\
\hline Acute respiratory failure & $10(19.61 \%)$ \\
\hline Shock & $7(13.73 \%)$ \\
\hline Acute renal failure & $5(9.80 \%)$ \\
\hline \multicolumn{2}{|l|}{ Reason for endotracheal intubation } \\
\hline Drug and/or alcohol poisoning & $9(17.65 \%)$ \\
\hline Hepatic encephalopathy & $5(9.80 \%)$ \\
\hline Post-extubation respiratory distress & $5(9.80 \%)$ \\
\hline Acute respiratory failure & $4(7.84 \%)$ \\
\hline Septic shock & $4(7.84 \%)$ \\
\hline Epileptic condition & $3(5.88 \%)$ \\
\hline Guillain-Barré syndrome & $3(5.88 \%)$ \\
\hline Myasthenia gravis & $2(3.92 \%)$ \\
\hline Encephalitis & $2(3.92 \%)$ \\
\hline Haemorrhagic shock & $2(3.92 \%)$ \\
\hline Acute pancreatitis & $2(3.92 \%)$ \\
\hline Delirium tremens & $1(1.96 \%)$ \\
\hline Meningitis & $1(1.96 \%)$ \\
\hline Inhalation pneumopathy & $1(1.96 \%)$ \\
\hline Haemorrhagic stroke & $1(1.96 \%)$ \\
\hline Other & $6(11.76 \%)$ \\
\hline SAPS ॥ & $46[30-62]$ \\
\hline SOFA score at ICU admission & $6[3-10]$ \\
\hline \multicolumn{2}{|c|}{ Arterial blood gas values at ICU admission $(n=30)$} \\
\hline $\mathrm{pH}$ & $7.39[7.27-7.45]$ \\
\hline $\mathrm{PaCO}_{2}, \mathrm{mmHg}$ & $37.13[28.50-43.50]$ \\
\hline $\mathrm{PaO}_{2}, \mathrm{mmHg}$ & $101.38[76-145.50]$ \\
\hline $\mathrm{PaO}_{2} / \mathrm{FiO}_{2}$ & $323[233-479]$ \\
\hline $\mathrm{SaO}_{2}, \%$ & $97.75[95.25-99.15]$ \\
\hline $\mathrm{CO}_{2}, \mathrm{mmol} / \mathrm{L}$ & $24.50[17.40-27.40]$ \\
\hline $\mathrm{SpO}_{2} / \mathrm{FiO}_{2}$ at ICU admission & $388[278-457]$ \\
\hline Arterial lactate, $\mathrm{mmol} \mathrm{L}^{-1}$ & $2.10[1.50-4.60]$ \\
\hline
\end{tabular}

The data are median [25th-75th percentiles] or number (percentage) ICU intensive care unit; SAPSII Simplified Acute Physiology Score version II; SOFA score Sequential Organ Failure Assessment score rocuronium in $9(17.6 \%)$ patients, with the remaining patient receiving no neuromuscular blocker. The operator was a resident for 48 (94.1\%) patients; residents were closely supervised by senior intensivists.

ETI was achieved in all patients, with a median number of attempts of $1[1,2]$ and a proportion of successful first attempts of $74.5 \%(n=38)$. In the remaining 13 patients, ETI was achieved after at least one additional attempt; the reasons for first-attempt failure were poor glottis visibility in $5(38.5 \%)$ patients and tracheal catheterisation failure in $8(61.5 \%)$ patients. ETI was difficult in $3(5.9 \%)$ patients (i.e., required at least three attempts). The only patient who needed more than three attempts was intubated on the seventh attempt. At the time of exposure, head elevation was required in 7 (13.7\%) patients, backwards-upwards-rightwards pressure (BURP) on the larynx in 14 (27.5\%) patients, and the Sellick manoeuvre in 3 (5.9\%) patients. The Cormack-Lehane grade was 1 or 2 in $45(88.2 \%)$ patients and 3 or 4 in $6(11.8 \%)$ patients. The median percentage of glottic opening seen (POGO) was 80 [70-100]. In 6 (11.8\%) patients, face-mask ventilation was required after the first attempt due either to desaturation $(n=3)$ or to first-attempt failure $(n=3)$. The median lowest $\mathrm{SpO}_{2}$ during intubation was 98\% [91-99] in patients who did not need face-mask ventilation and $72 \%$ [55-82] in those who did require face-mask ventilation before ETI. $\mathrm{SpO}_{2}$ fell below $97 \%$ in 20 patients.

ETI-related complications occurred in 24 (24/51, $47.1 \%)$ patients. By decreasing order of frequency, they consisted of arterial hypotension $(n=18,75 \%)$, moderate hypoxemia $\left(\mathrm{SpO}_{2}<90 \%, n=9,37.5 \%\right)$, severe hypoxemia $\left(\mathrm{SpO}_{2}<80 \%, n=4,16.7 \%\right)$, oesophageal intubation $(n=2,8.3 \%)$, and aspiration $(n=1,4.1 \%)$. No patient had cardiorespiratory arrest or death due to ETI.

Overall, 9 (17.6\%) patients died in the ICU. On day 28, $42(82.4 \%)$ patients were alive. The median ICU length of stay was 5.36 days [2.9-15.8].

\section{Primary outcome}

Of the 51 patients, 20 experienced an $\mathrm{SpO}_{2}$ fall below 97\% between the end of preoxygenation and successful ETI. An ORI fall below 0.4 preceded this $\mathrm{SpO}_{2}$ fall under $97 \%$ in 10 of these patients. In the other 10 patients, when the $\mathrm{SpO}_{2}$ fall below 97\% occurred, the ORI had not increased above 0.4 . In the 10 patients with a warning ORI fall below 0.4 before the $\mathrm{SpO}_{2}$ fall below $97 \%$, the median time between these two events was $81 \mathrm{~s}$ [34-146] and the median ETI duration was 303 s [180-648].

\section{Secondary outcomes}

As noted above, of the 51 patients, 20 (39.2\%) experienced $\mathrm{SpO}_{2}<97 \%$ during intubation. Table 2 and Figs. 1 
Table 2 Comparison of peripheral oxygen saturation $\left(\mathrm{SpO}_{2}\right)$ and oxygen reserve index (ORI) in patients with and without $\mathrm{SpO} 2<97 \%$ during endotracheal intubation (ETI)

\begin{tabular}{|c|c|c|c|c|}
\hline & Total $n=51$ & $\mathrm{SpO}_{2} \geq 97 \% n=31$ & $\mathrm{SpO}_{2}<97 \% n=20$ & $P$ value \\
\hline $\mathrm{SpO}_{2}$ at the start of preoxygenation, median [IQR] & $97.00[95.00-99.00]$ & $98.00[95.00-100.00]$ & $97.00[95.00-97.00]$ & 0.0951 \\
\hline $\mathrm{SpO}_{2}$ at the end of preoxygenation, median [IQR] & $100.00[99.00-100.00]$ & $100.00[99.00-100.00]$ & $100.00[99.00-100.00]$ & 0.5931 \\
\hline $\mathrm{SpO}_{2}$ at ETI, median [IQR] & $99.00[95.00-100.00]$ & $100.00[99.00-100.00]$ & $93.00[85.50-97.00]$ & $<0.0001$ \\
\hline ORl at the start of preoxygenation, median [IQR] & $0.04[0.01-0.13]$ & $0.05[0.02-0.20]$ & $0.04[0.01-0.12]$ & 0.2891 \\
\hline ORl at the end of preoxygenation, median [IQR] & $0.62[0.26-0.83]$ & $0.71[0.54-0.94]$ & $0.39[0.15-0.65]$ & 0.0082 \\
\hline Change in ORI from start to end of preoxygenation, median [IQR] & $0.46[0.15-0.64]$ & $0.52[0.23-0.82]$ & $0.17[0.10-0.50]$ & 0.0191 \\
\hline Highest ORI during preoxygenation, median [IQR] & $0.67[0.31-0.94]$ & $0.77[0.59-1.00]$ & $0.49[0.22-0.77]$ & 0.0212 \\
\hline Changes in $\mathrm{SpO}_{2}$ from start to end of preoxygenation, median [IQR] & $3.00[1.00-4.00]$ & $2.00[0.00-4.00]$ & $3.00[2.00-5.00]$ & 0.1181 \\
\hline
\end{tabular}

$\mathrm{SpO}_{2}$ oxygen saturation by pulse oximeter; IQR interquartile range; $E T I$ endotracheal intubation; $O R I$ oxygen reserve index

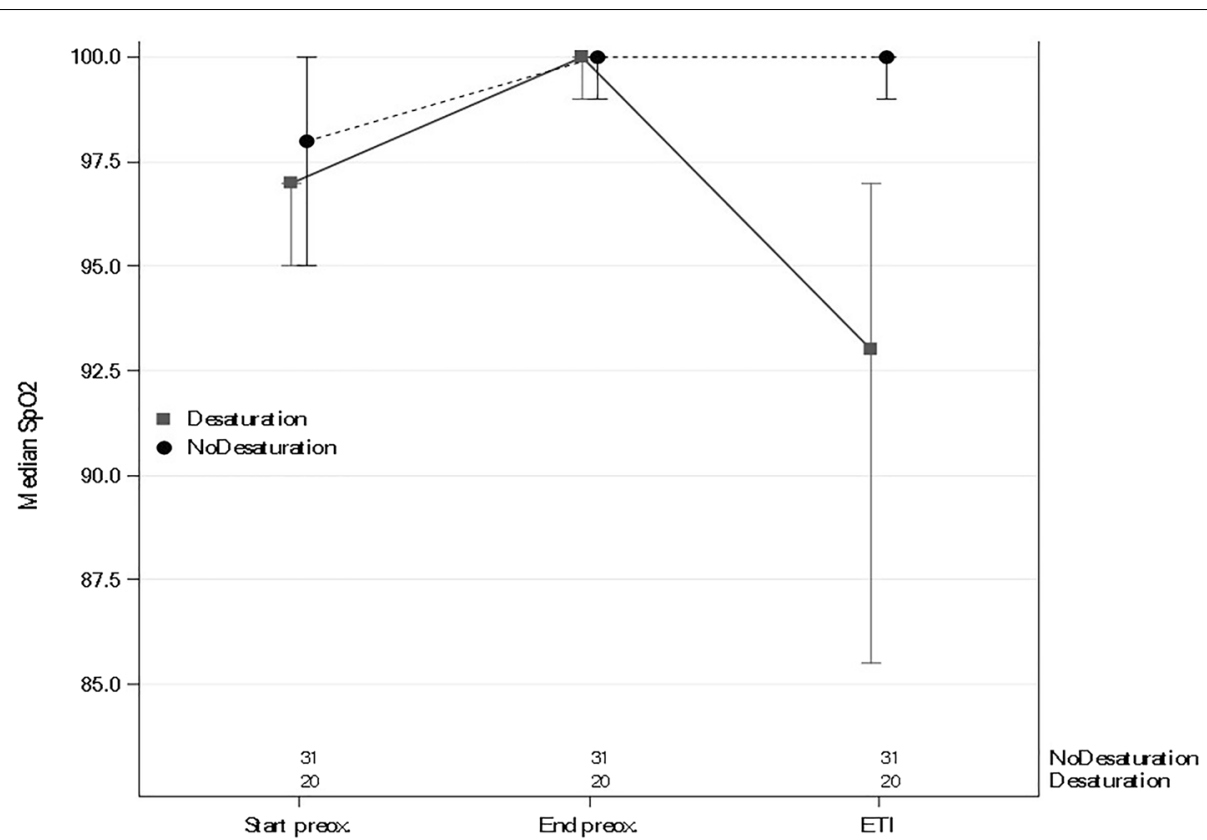

Fig. $1 \mathrm{SpO}_{2}$ changes during preoxygenation and endotracheal intubation (ETI)

and 2 show the changes in $\mathrm{SpO}_{2}$ and ORI from the start of preoxygenation to the end of intubation. Additional file 2: Figure S2 shows changes in $\mathrm{SpO}_{2}$ and ORI in the subset of patients who had moderate hypoxemia and Additional file 3: Figure S3 shows changes in all patients.

The areas under the ROC curve for ORI during preoxygenation and at the end of preoxygenation predicted the occurrence of $\mathrm{SpO}_{2}<97 \%$ during intubation $(0.73 ; 95 \%$ CI $0.58-0.88$ and 0.70 ; $95 \%$ CI $0.54-0.85$, respectively). In contrast, the area under the $\mathrm{ROC}$ curve of $\mathrm{SpO}_{2}$ at the end of preoxygenation was poorly predictive of $\mathrm{SpO}_{2}<$ $97 \%$ during intubation $(0.54 ; 95 \%$ CI $0.40-0.67)$.

By univariate analysis, longer ETI duration was associated with the occurrence of $\mathrm{SpO}_{2}<97 \%$ during intubation (odds ratio, 1.00; 95\% CI 1.00-1.01; $P=0.0474$ ), whereas a higher ORI value during preoxygenation was associated with a less frequent occurrence of $\mathrm{SpO}_{2}<97 \%$ (odds ratio, 0.09; 95\% CI 0.01-0.69; $P=$ 0.0199 ). The highest ORI value during preoxygenation remained significantly associated with a lower risk of $\mathrm{SpO}_{2}<97 \%$ during ETI after adjustment for ETI duration and BMI (odds ratio, 0.76; 95\% CI 0.61-0.95; $P=$ 0.0141; Table 3).

\section{Discussion}

The main findings from our study are that in critically ill patients who require ETI, are not hypoxemic, and whose ORI is above 0.4 during preoxygenation, the median 


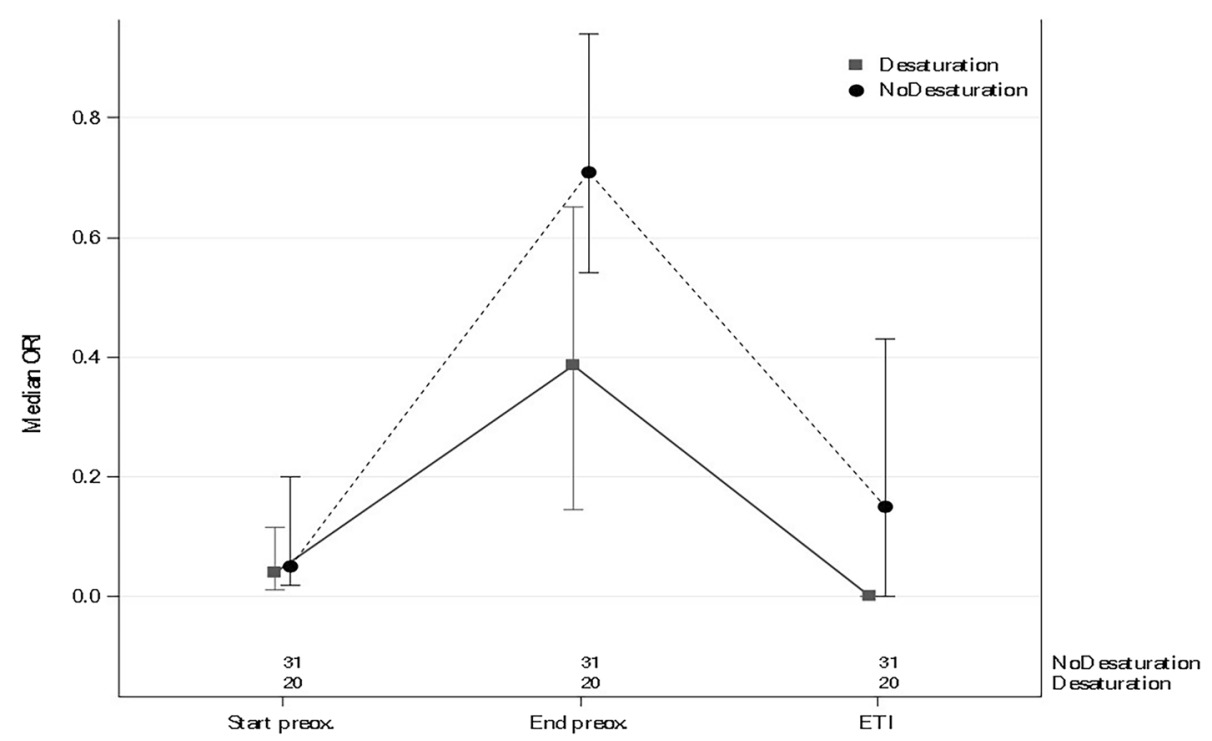

Fig. 2 Changes in oxygen reserve index (ORI) in patients with and without hypoxemia during endotracheal intubation (ETI)

Table 3 Multivariable analysis: factors associated with $\mathrm{SpO}_{2}<$ 97\% during endotracheal intubation (ETI)

\begin{tabular}{llll}
\hline Variable & OR & $\mathbf{9 5 \% ~ C l}$ & P value \\
\hline Duration of ETI (seconds) & 1.00 & {$[1.00 ; 1.01]$} & 0.0494 \\
BMI $>25 \mathrm{~kg} \cdot \mathrm{m}^{-2}$ & 1.73 & {$[0.45 ; 6.65]$} & 0.1295 \\
Highest ORI during preoxygenation & 0.76 & {$[0.61 ; 0.95]$} & 0.0141 \\
\hline
\end{tabular}

OR odds ratio; $95 \% \mathrm{Cl}$ 95\% confidence interval; ETI endotracheal intubation; BMI body mass index; $O R I$ oxygen reserve index

time between the ORI decrease below 0.4 and the $\mathrm{SpO}_{2}$ decrease below $97 \%$ was $81 \mathrm{~s}$ [34-146] and that, by multivariate analysis, a higher ORI value during preoxygenation was associated with a lower risk of desaturation below 97\% during ETI, after adjustment on ETI duration. The median highest ORI value during preoxygenation was higher in the group without desaturation below 97\%. In contrast, no differences between the two groups were found for the $\mathrm{SpO}_{2}$ values at the beginning or end of preoxygenation or for the change in $\mathrm{SpO}_{2}$ between the beginning and end of preoxygenation.

Our results are consistent with those found in patients undergoing elective surgery, which were prospective observational studies with small sample sizes. Reported time intervals between the ORI decline and desaturation were 31.5 [19.0-34.3] s [22], 32.5 [18.8-51.3] s [20], and 48.4 [40.4-62.0] s [22]. Thus, the warning time in patients without critical illness was shorter than in our cohort. Possible explanations are the variations in cut-offs chosen to define hypoxemia, inclusion of children in some studies, use of the latest sensor model (revision $\mathrm{M}$ of revision
L) in our study, possible continuation of oxygenation during the apneic period in previous studies, and/or successful ETI in some patients after a failed first attempt but before the occurrence of decreases in ORI and $\mathrm{SpO}_{2}$.

$\mathrm{SpO}_{2}$ changes during preoxygenation serve as a proxy for $\mathrm{PaO}_{2}$ changes, but neither evaluate the oxygen reserve nor predict hypoxemia during ETI [26]. $\mathrm{SpO}_{2}$ values may even be falsely reassuring: in our study, the median $\mathrm{SpO}_{2}$ at the end of preoxygenation was $100 \%$ [99-100] in both groups. The fraction of oxygen in expired air $\left(\mathrm{FeO}_{2}\right)$ can also provide information on the oxygen reserve [27]: an $\mathrm{FeO}_{2}$ of $90 \%$ is taken to indicate denitrogenation of the functional residual capacity (FRC). In the operating room, preoxygenation for $3 \mathrm{~min}$ is usually sufficient to bring $\mathrm{FeO}_{2}$ up to $90 \%$. However, this technique has limitations in the emergency setting, as it is sensitive to leaks, and is not available in the ICU [13]. Moreover, in critically ill patients, particularly those with acute hypoxemic respiratory failure (who were excluded for this proof-of concept study), $\mathrm{FeO}_{2}$ may not reliably reflect the effectiveness of preoxygenation: the reduction in functional lung volume leads, on the one hand, to a reduction in FRC and, on the other hand, to shunting that impairs the efficiency of the alveolar-capillary interface [28]. The result is that both $\mathrm{SpO}_{2}$ and $\mathrm{FeO}_{2}$ can be high despite $\mathrm{PaO}_{2}$ being low. $\mathrm{PaO}_{2}$ can be considered the reference standard for evaluating the effectiveness of preoxygenation but, unfortunately, cannot currently be obtained at the bedside in real-time in clinical practice [13].

We chose the $\mathrm{SpO}_{2} / \mathrm{FiO}_{2}$ ratio as the inclusion criterion because it was simpler to use than the $\mathrm{PaO}_{2} / \mathrm{FiO}_{2}$ ratio, 
as obtaining an arterial blood sample may be difficult in emergency situations. The 214 cut-off was chosen as corresponding to a $\mathrm{PaO}_{2} / \mathrm{FiO}_{2}$ ratio greater than 180 [29]. Including patients with more severe hypoxemia may not have allowed for ORI increases to occur in both groups during preoxygenation. We defined mild hypoxemia as $\mathrm{SpO}_{2}$ below $97 \%$, as this value corresponds to the inflection point towards a rapid decrease in $\mathrm{SpO}_{2}$ during the apneic period [24] and to an ORI value of 0 indicating an absence of oxygen reserves [18].

The clinical implications of our findings may be important. The 81-s forewarning may allow immediate intubation, early face-mask ventilation, insertion of a supraglottic device, or a call for help in the event of intubation difficulties. In addition, ORI monitoring can help identify patients who do not increase their oxygen reserve despite preoxygenation and are therefore at risk of desaturation during ETI. These patients may benefit from a longer preoxygenation period and/or a change in device. An ORI decline might lead to the detection of a fault in the preoxygenation technique such as an insufficient oxygen flow rate or major leaks. The clinical impact of an ORI-guided airway management and preoxygenation strategy remains to be evaluated prospectively.

Our work has several limitations. First, the sample size is small. We had estimated that at least 35 patients had to be included in the analysis to compute the median time from the ORI decrease to the $\mathrm{SpO}_{2}$ decrease. However, only 10 of our patients exhibited both ORI $<0.4$ and $\mathrm{SpO}_{2}<97 \%$ during intubation, and 10 patients did not have an ORI increase $>0.4$ during preoxygenation. Second, 5 patients, representing $9 \%$ of the initial cohort, were excluded secondarily due to either a malfunction of the ORI system or a failure of the $\operatorname{Rad} 7^{\circledR}$ monitor to record the ORI. Third, at the beginning of preoxygenation, the ORI value had already started to increase and was therefore not equal to 0 in either group. However, there was no significant difference in ORI values at this time point between the two groups. Fourth, our results cannot be generalised to all ICU patients. We selected patients with $\mathrm{SpO}_{2}<$ 97\% and no haemodynamic failure who required ETI mainly to protect the upper airway due to neurological failure. The incidence of hypoxemia during ETI is lower in this population than in patients with respiratory failure. Studies in patients with hypoxemia are therefore necessary. Fifth, as with pulse oximetry, ORI measurement can be unreliable in situations where the peripheral perfusion is impaired, such as in the event of shock or high-dose vasopressor therapy. Sixth, significant inter-individual variability is likely, as some factors may affect the calculation of ORI and therefore alter the relationship between $\mathrm{PaO}_{2}$ and ORI. These factors include oxygen consumption, cardiac output, temperature, $\mathrm{pH}, \mathrm{PaCO}_{2}$, presence of abnormal haemoglobin, and venous pulsatility.

\section{Conclusion}

The median time between the ORI decrease below 0.4 and the $\mathrm{SpO}_{2}$ decrease below 97\% during the apneic period was $81 \mathrm{~s}$ [34-146]. A higher ORI during preoxygenation was independently associated with a lower risk of mild hypoxemia $\left(\mathrm{SpO}_{2}<97 \%\right)$. Whether these findings apply to hypoxemic patients, and the clinical impact of a preoxygenation strategy based on ORI monitoring, remain to be evaluated prospectively.

\section{Supplementary Information}

The online version contains supplementary material available at https://doi. org/10.1186/s13613-021-00903-8.

Additional file 1: Figure S1. Study flowchart

Additional file 2: Figure S2. Changes in $\mathrm{SpO}_{2}$ and the oxygen reserve index (ORI) in the subset of patients who had moderate hypoxemia $\left(\mathrm{SpO}_{2}\right.$ $<90 \%)$.

Additional file 3: Figure S3. Changes in $\mathrm{SpO}_{2}$ and the oxygen reserve index (ORI) in the overall cohort.

\section{Acknowledgements}

We thank M. Rouaud, MSc, for her help during administrative process. We are indebted to A. Wolfe, MD, who helped to prepare and review the manuscript. We thank E. Billaud for his help during reception of devices.

\section{Authors' contributions}

Study design, development and study set-up were performed by $\mathrm{HH}, \mathrm{EC}$, $J \mathrm{~L}, \mathrm{LC}, \mathrm{GO}, \mathrm{CG}, \mathrm{MM}, \mathrm{AS}, \mathrm{OZ}, \mathrm{AFM}, \mathrm{JR}$ and JBL. HH, JR, and JBL were in charge of site set-up, patient enrolment, data collection, and research governance. ALT performed the statistical analysis. The initial draft of the manuscript was written by $\mathrm{HH}, \mathrm{ALT}$, and JBL. All authors reviewed this and subsequent versions of the manuscript for important intellectual content. All authors vouch for the accuracy and completeness of the data and analyses and for the fidelity of the trial to the protocol. All authors read and approved the final manuscript.

\section{Funding}

Not funded.

Availability of data and materials

The study data will be made available upon reasonable request to the corresponding author.

\section{Code availability}

Not applicable.

\section{Declarations}

\section{Ethics approval and consent to participate}

The study was approved by our ethics committee on July 17, 2018 (CPP Ile de France 1, ID-RCB: 2018-A01288-47) and was registered on ClinicalTrial.gov on July 24, 2018 (\#NCT03600181). Informed consent was obtained from each patient or proxy before study inclusion.

Consent for publication

Not applicable. 


\section{Competing interests}

The Rad7 monitors and Rainbow SET devices were provided free of charge by Masimo Inc., Irvine, CA. Masimo Inc. had no role in the study design or conduct; data collection, management, analysis, or interpretation; preparation, review, or approval of the manuscript; or decision to submit the manuscript for publication.

\section{Author details}

'Médecine Intensive Réanimation, Centre Hospitalier Universitaire de Nantes, Nantes, France. ${ }^{2}$ Plateforme de Méthodologie Et Biostatistique, Direction de La Recherche de L'Innovation, Centre Hospitalier Universitaire de Nantes, Nantes, France. ${ }^{3}$ Paris Cardiovascular Research Centre, Université de Paris, INSERM, Paris, France. ${ }^{4}$ Service de Médecine Intensive Réanimation, Centre Hospitalier Universitaire Hôtel-Dieu, 30 Bd. Jean Monnet, 44093 Nantes Cedex 1, France.

Received: 12 April 2021 Accepted: 6 July 2021

Published online: 17 July 2021

\section{References}

1. Jaber S, Amraoui J, Lefrant JY, Arich C, Cohendy R, Landreau L, et al. Clinical practice and risk factors for immediate complications of endotracheal intubation in the intensive care unit: a prospective, multiple-center study. Crit Care Med. 2006;34:2355-61.

2. Schwartz DE, Matthay MA, Cohen NH. Death and other complications of emergency airway management in critically ill adults. A prospective investigation of 297 tracheal intubations. Anesthesiology. 1995:82:367-76.

3. Martin M, Decamps P, Seguin A, Garret C, Crosby L, Zambon O, et al. Nationwide survey on training and device utilization during tracheal intubation in French intensive care units. Ann Intensive Care. 2020;10:2.

4. Russotto V, Myatra SN, Laffey JG, Tassistro E, Antolini L, Bauer P, et al. Intubation practices and adverse peri-intubation events in critically ill patients from 29 countries. JAMA. 2021:325:1164-72.

5. Lascarrou JB, Boisrame-Helms J, Bailly A, Le Thuaut A, Kamel T, Mercier E, et al. Video laryngoscopy vs direct laryngoscopy on successful first-pass orotracheal intubation among icu patients: a randomized clinical trial. JAMA. 2017:317:483-93.

6. Frat JP, Ricard JD, Quenot JP, Pichon N, Demoule A, Forel JM, et al. Noninvasive ventilation versus high-flow nasal cannula oxygen therapy with apnoeic oxygenation for preoxygenation before intubation of patients with acute hypoxaemic respiratory failure: a randomised, multicentre, open-label trial. Lancet Respir Med. 2019;7:303-12.

7. De Jong A, Rolle A, Molinari N, Paugam-Burtz C, Constantin JM, Lefrant $J Y$, et al. Cardiac arrest and mortality related to intubation procedure in critically ill adult patients: a multicenter cohort study. Crit Care Med. 2018:46:532-9.

8. Heuer JF, Barwing TA, Barwing J, Russo SG, Bleckmann E, Quintel M, et al. Incidence of difficult intubation in intensive care patients: analysis of contributing factors. Anaesth Intensive Care. 2012:40:120-7.

9. Mort TC. Emergency tracheal intubation: complications associated with repeated laryngoscopic attempts. Anesth Analg. 2004;99:607-13.

10. McKown AC, Casey JD, Russell DW, Joffe AM, Janz DR, Rice TW, et al. Risk factors for and prediction of hypoxemia during tracheal intubation of critically ill adults. Ann Am Thorac Soc. 2018;15:1320-7.

11. Higgs A, McGrath BA, Goddard C, Rangasami J, Suntharalingam G, Gale R, et al. Guidelines for the management of tracheal intubation in critically ill adults. Br J Anaesth. 2018;120:323-52.

12. Quintard H, I'Her E, Pottecher J, Adnet F, Constantin JM, De Jong A, et al. Experts' guidelines of intubation and extubation of the ICU patient of French Society of Anaesthesia and Intensive Care Medicine (SFAR) and French-speaking Intensive Care Society (SRLF) : In collaboration with the pediatric Association of French-speaking Anaesthetists and Intensivists (ADARPEF), French-speaking Group of Intensive Care and Paediatric emergencies (GFRUP) and Intensive Care physiotherapy society (SKR). Ann Intensive Care. 2019;9:13.

13. Mosier JM, Hypes CD, Sakles JC. Understanding preoxygenation and apneic oxygenation during intubation in the critically ill. Intensive Care Med. 2017:43:226-8.

14. Bailly A, Ricard JD, Le Thuaut A, Helms J, Kamel T, Mercier E, et al. Compared efficacy of four preoxygenation methods for intubation in the icu: retrospective analysis of McGrath Mac videolaryngoscope versus Macintosh laryngoscope (macman) trial data. Crit Care Med. 2019;47:340.

15. Vourc'h M, Asfar P, Volteau C, Bachoumas K, Clavieras N, Egreteau PY, et al. High-flow nasal cannula oxygen during endotracheal intubation in hypoxemic patients: a randomized controlled clinical trial. Intensive Care Med. 2015;41:1538-48.

16. Guitton C, Ehrmann S, Volteau C, Colin G, Maamar A, Jean-Michel V, et al. Nasal high-flow preoxygenation for endotracheal intubation in the critically ill patient: a randomized clinical trial. Intensive Care Med. 2019:45:447-58.

17. Mort TC, Waberski BH, Clive J. Extending the preoxygenation period from 4 to 8 mins in critically ill patients undergoing emergency intubation. Crit Care Med. 2009;37:68-71.

18. Scheeren TWL, Belda FJ, Perel A. The oxygen reserve index (ORI): a new tool to monitor oxygen therapy. J Clin Monit Comput. 2018;32:379-89.

19. Coudroy R, Frat J-P, Girault C, Thille AW. Reliability of methods to estimate the fraction of inspired oxygen in patients with acute respiratory failure breathing through non-rebreather reservoir bag oxygen mask. Thorax. 2020;75:805-7.

20. Yoshida K, Isosu T, Noji Y, Hasegawa M, Iseki Y, Oishi R, et al. Usefulness of oxygen reserve index $\left(\mathrm{ORi}^{\mathrm{TM}}\right)$, a new parameter of oxygenation reserve potential, for rapid sequence induction of general anesthesia. J Clin Monit Comput. 2018;32:687-91.

21. Jaber S, De Jong A, Pelosi P, Cabrini L, Reignier J, Lascarrou JB. Videolaryngoscopy in critically ill patients. Crit Care. 2019;23:221.

22. Szmuk P, Steiner JW, Olomu PN, Ploski RP, Sessler DI, Ezri T. Oxygen reserve index: a novel noninvasive measure of oxygen reserve-a pilot study. Anesthesiology. 2016;124:779-84.

23. Casey JD, Janz DR, Russell DW, Vonderhaar DJ, Joffe AM, Dischert KM, et al. Bag-mask ventilation during tracheal intubation of critically ill adults. N Engl J Med. 2019;380:811-21.

24. Fleming NW, Singh A, Lee L, Applegate RL. Oxygen reserve index: utility as an early warning for desaturation in high-risk surgical patients. Anesth Analg. 2020;132:770.

25. Ye T, Yi Y. Sample size calculations in clinical research, third edition, by Shein-Chung Chow, Jun Shao, Hansheng Wang, and Yuliya Lokhnygina. Stat Theory Relat Fields. 2017;1:265-6.

26. Jubran A. Pulse oximetry. Crit Care. 2015;19:272.

27. Caputo ND, Oliver M, West JR, Hackett R, Sakles JC. Use of end tidal oxygen monitoring to assess preoxygenation during rapid sequence intubation in the emergency department. Ann Emerg Med Elsevier. 2019:74:410-5.

28. Menk M, Estenssoro E, Sahetya SK, Neto AS, Sinha P, Slutsky AS, et al. Current and evolving standards of care for patients with ARDS. Intensive Care Med. 2020;46:2157-67.

29. Rice TW, Wheeler AP, Bernard GR, Hayden DL, Schoenfeld DA, Ware LB. Comparison of the $\mathrm{SpO}_{2} / \mathrm{FIO}_{2}$ ratio and the $\mathrm{PaO}_{2} / \mathrm{FIO}_{2}$ ratio in patients with acute lung injury or ARDS. Chest. 2007;132:410-7.

\section{Publisher's Note}

Springer Nature remains neutral with regard to jurisdictional claims in published maps and institutional affiliations. 